\title{
Synthesis of polyaniline coating on the modified fiber ball and application for $\mathrm{Cr}(\mathrm{VI})$ removal
}

\section{Xiao Li}

Institute of Solid State Physics, Hefei Institutes of Physical Science,Chinese Academy of

Science,P.R.China

\section{Guang Tao Fei ( $\nabla$ gtfei@issp.ac.cn )}

Institute of Solid State Physics, Hefei Institutes of Physical Science, Chinese Academy of Sciences https://orcid.org/0000-0002-4657-1285

\section{Shao Hui Xu}

Institute of Solid State Physics,Hefei Institutes of Physical Science,Chinese Academy of Science,P.R.China

\section{Research Article}

Keywords: Polyaniline, Fiber ball, Chromium, Adsorption, Regeneration

Posted Date: February 23rd, 2021

DOl: https://doi.org/10.21203/rs.3.rs-182371/v1

License: (c) (1) This work is licensed under a Creative Commons Attribution 4.0 International License. Read Full License

Version of Record: A version of this preprint was published at Nanoscale Research Letters on April 8th, 2021. See the published version at https://doi.org/10.1186/s11671-021-03509-y. 
1 Synthesis of polyaniline coating on the modified fiber ball

2 and application for $\operatorname{Cr}(\mathrm{VI})$ removal

3

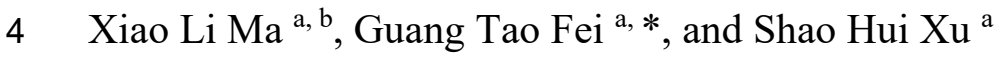

5

6 a. Key Laboratory of Materials Physics and Anhui Key Laboratory of Nanomaterials and Nanotechnology, Institute of Solid State Physics, Hefei Institutes of Physical

8 Science, Chinese Academy of Sciences, P. O. Box 1129, Hefei 230031, P. R. China.

9 b. University of Science and Technology of China, Hefei 230026, P. R. China.

10

\section{E-mail address of each author}

Xiao Li Ma: mxlmary@mail.ustc.edu.cn

Guang Tao Fei: gtfei@issp.ac.cn

Shao Hui Xu: shxu@issp.ac.cn

\section{*Corresponding author}

Guang Tao Fei

Postal address: Institute of Solid State Physics, Chinese Academy of Sciences, P.O.

Box 1129, Hefei 230031, P. R. China

Telephone: 86-551-65591453

Fax: 86-551-65591434

Email: gtfei@issp.ac.cn 
1 Abstract

In this study, polyaniline (PANI) is prepared by means of chemical oxidization polymerization and directly loaded on the modified fiber ball (m-FB) to obtain macroscale polyaniline/modified fiber ball (PANI/m-FB) composite, and then its removal ability of $\mathrm{Cr}(\mathrm{VI})$ is investigated. The effects of different parameters such as contact time, $\mathrm{pH}$ value and initial concentration on $\mathrm{Cr}(\mathrm{VI})$ removal efficiency are discussed. The experimental results illustrate that the favourable $\mathrm{pH}$ value is 5.0 and the maximum removal capacity is measured to be $293.13 \mathrm{mg} \cdot \mathrm{g}^{-1}$. Besides, PANI/m-FB composites can be regenerated and reused after being treated with strong acid. The kinetic study indicates that the adsorption procedure is mainly controlled by chemical adsorption. More importantly, the macroscale of composites can avoid secondary pollution efficiently. Benefiting from the low cost, easy preparation in large scale, environmentally friendly, excellent recycling performance as well as high removal ability, PANI/m-FB composites exhibit a potential possibility to remove $\mathrm{Cr}(\mathrm{VI})$ from industrial waste water.

Keywords: Polyaniline, Fiber ball, Chromium, Adsorption, Regeneration 


\section{Background}

With the rapid development of industry, the environmental contamination has been more and more serious, and the pollution caused by heavy metal ions is one of the most severe challenges that humans have to conquer with [1]. Particularly, hexavalent chromium $[\mathrm{Cr}(\mathrm{VI})]$, which resulted from electroplating, textile printing and mordanting, can generate great damage to the environment and even human health due to its high toxicity, carcinogenic effects, easy mobility, and ability of accumulation in ecosystem and human body [2-4]. Compared with $\mathrm{Cr}(\mathrm{VI})$, the toxicity of $\mathrm{Cr}(\mathrm{III})$ is much less than that of $\mathrm{Cr}(\mathrm{VI})$ and easier to be removed by adsorption and precipitation [3]. Hence, the deoxidation of $\mathrm{Cr}(\mathrm{VI})$ to less poisonous $\mathrm{Cr}(\mathrm{III})$ and then adsorption and precipitation prior to its discharge to the environment is essential to ensure the protection of aquatic lives and human in current researches [5-9].

It is reported that polyaniline (PANI) has a prominent ability that can reduce $\mathrm{Cr}(\mathrm{VI})$ to $\mathrm{Cr}$ (III) due to its distinct oxidation characteristic, higher reaction rate and better stability [10]. Besides, PANI contains plentiful positively charged amine and imine groups which can be utilized as a promising adsorption material to adsorb the $\mathrm{Cr}(\mathrm{III})$ as the reduction product of $\mathrm{Cr}(\mathrm{VI})$. So, there have been a great deal of research towards the use of PANI for $\mathrm{Cr}(\mathrm{VI})$ removal due to its easy synthesis, low cost, remarkable environmental stability and reversibility [11-13]. Up to now, people have fabricated various morphologies of polyaniline like polyaniline films, polyaniline nanowires, polyaniline-based composites and so on $[11,14-18]$. Whereas, there are still many problems desiring to be solved. For one thing, the specific surface areas of PANI films are relatively small resulting in a decreasing contact with $\mathrm{Cr}(\mathrm{VI})$ solution and limiting the removal capacity [19]. For another, compared with the films, although the removal capacities of PANI nanowires and polyaniline-based composites have enhanced 
1 enormously due to the large specific surface area, the sizes of these materials are too

2 small to be recycled totally and it can cause secondary pollution in industrialized

3 application. Hence, how to effectively solve the problem of secondary pollution while

4 improving the removal capacity in order to make it widely used in industrial wastewater

5 treatment rather than just in laboratory research is still a great challenge. Up to now,

6 however, far too little attention has been paid to this aspect.

Fiber ball (FB), consisting of polyester or polyacrylonitrile fiber, is a kind of

8 sphere structure caused by the curving of long fibres through the method of fabricating

9 non-woven fabrics. As a burgeoning technology in water treatment, fiber ball has been

10 widely applied to industrial waste water treatment, drinking water treatment and

11 seawater treatment due to its low cost, good elasticity, stable physical and chemical

12 properties, strong pollutant interception ability and fast filter speed [20-22]. More

13 importantly, this kind of macroscale fiber ball will not generate secondary pollution at

14 all so that if we load PANI on the surface of fiber ball to obtain polyaniline/fiber ball

15 (PANI/FB) composites, the problem of secondary pollution caused by nanoscale PANI

16 will be solved.

17 The aim of this study is to solve secondary pollution caused by PANI at nanoscale

18 during the process of $\mathrm{Cr}(\mathrm{VI})$ treatment and realize the regeneration and recycle of

19 adsorbents. Herein, PANI is prepared and directly loaded on the macroscale modified

20 fiber ball (m-FB) to obtain the PANI/m-FB composite. The experimental results show

21 that PANI is firmly combined with fiber balls and the PANI/m-FB composite not only

22 exhibits an effective removal capacity of $\mathrm{Cr}(\mathrm{VI})$ in aqueous solution, but also can be

23 regenerated and reused. Hence, it is more beneficial to the extension of industrialization

24 considering the fact of its easy synthesis, remarkable environmental stability and

25 reversibility [23,24]. 
Methods

\section{Materials}

Aniline, ammonium persulfate (APS), tartaric acid (TA), sulfuric acid $\left(\mathrm{H}_{2} \mathrm{SO}_{4}\right)$, hydrogen peroxide $\left(\mathrm{H}_{2} \mathrm{O}_{2}\right)$ and potassium dichromate $\left(\mathrm{K}_{2} \mathrm{Cr}_{2} \mathrm{O}_{7}\right)$ were all purchased from Aladdin biochemical technology Co., LTD., Shanghai, China. All the reagents were analytically pure and were used without further purification. Fiber balls (FB) which mainly composed of polyester fibers were obtained commercially from Yijia water purification material Co., LTD. in Henan, China. All the solutions were prepared by deionized water.

\section{Preparation of modified fiber ball (m-FB)}

Firstly, fiber balls were soaked into deionized water for 1 hour at room temperature and cleaned in ultrasonic washing units for 20 min three times to remove the dust or impurities, and then dried at $60^{\circ} \mathrm{C}$ in drying oven for $12 \mathrm{~h}$. Subsequently, fiber balls were immerged in $10 \mathrm{~g} \cdot \mathrm{L}^{-1} \mathrm{H}_{2} \mathrm{O}_{2}$ solution and stirred for $24 \mathrm{~h}$ at room temperature in order to modify the surface of fiber balls. And then modified fiber balls were rinsed by deionized water three times again and then dried at $60^{\circ} \mathrm{C}$ in drying oven for $12 \mathrm{~h}$.

\section{Preparation of PANI/m-FB composites}

Aniline $(4 \mathrm{~mL})$ and tartaric acid $(0.1 \mathrm{~mol})$ were dissolved in $100 \mathrm{ml}$ deionized water at room temperature with magnetic stirring for $15 \mathrm{~min}$, and APS (0.4 mol) was dispersed in $100 \mathrm{ml}$ deionized water as well. After placing the aniline solution as well as APS solution in an ice bath for $5 \mathrm{~min}$, respectively, APS solution was poured into aniline solution slowly and then put the modified fiber ball into the mixed solution [11]. Next, the reaction mixture was put in an ice bath and then the chemical oxidative 
1 polymerization took place. After 24 hours, the products were purified by filtering and

2 rinsing with deionized water and alcohol for several times to remove the excess acid

3 and by-products. Finally, the resulting composites were dried at $60^{\circ} \mathrm{C}$ in drying oven

4 for $12 \mathrm{~h}$.

5 For comparison, we prepared PANI/FB composites and the preparation procedure

6 was similar to that of PANI/m-FB composites except for the modification of fiber ball.

7

\section{Characterization of PANI/m-FB composites}

The morphology of PANI/m-FB was characterized by field emission scanning electron microscope (FESEM, Horiba Company in Japan, SU8020). The molecular structure and functional groups were characterized by the Fourier transform infrared spectroscopy (FT-IR, JASCO FT-IR 410) in the range of 500 to $4000 \mathrm{~cm}^{-1}$ at a resolution of $4 \mathrm{~cm}^{-1}$. The optical absorbance of $\mathrm{Cr}(\mathrm{VI})$ solution was tested by ultravioletvisible spectrophotometer (UV-Vis, UV1750) and the oxidation state of chromium adsorbed on composites was analyzed by X-ray photoelectron spectra (XPS, Thermo ESLCALAB 250Xi).

\section{Results and Discussion}

Fig.1(a) to (d) exhibit the SEM images and the digital camera photo of the samples, respectively. Fig.1(a) and (b) illustrate the microstructure of PANI/m-FB and PANI/ FB composites, respectively, and it can be noticed that PANI coated on the modified fiber ball was more homogeneous, indicating that modification can enhance the ability of fiber ball to load PANI. Furtherly, Fig.1(c) is the enlarged picture of Fig.1(a) and from Fig.1(c), it can be seen that the morphology of PANI is mainly composed of one- 
1 dimensional nanostructure with the diameter of about $190 \pm 10 \mathrm{~nm}$. Besides, Fig.1(d)

2 shows the macrostructure image of fiber ball before and after coated by PANI.

To investigate the load capacity of fiber ball, we chose three different groups of

4 modified fiber balls and weighed their weights. Then, we loaded PANI on them under

5 the same condition to obtain PANI/m-FB composites and numbered them as Sample-1

6 to Sample-3. For comparison, we measured the load rate of PANI/FB composites and

7 marked as Sample-4 in the same way. After cleaned by deionized water in ultrasonic

8 washing units for 10 min several times, the weight was measured and the results are

9 shown in Table 1. It can be concluded that the average PANI load rate of modified fiber

10 ball is about 5.65\%, which is much superior to the fiber ball without modification. So,

11 we selected modified fiber balls to load PANI in the subsequent experiments.

Table 1 The PANI load rate of fiber balls

\begin{tabular}{c|c|c|c|c}
\hline & Sample-1 & Sample-2 & Sample-3 & Sample-4 \\
\hline $\mathbf{m}_{\mathbf{0}}(\mathbf{g})$ & 4.3030 & 3.5680 & 3.6771 & 3.7177 \\
\hline $\mathbf{m}_{\mathbf{1}} \mathbf{( g )}$ & 4.5565 & 3.7725 & 3.8735 & 3.8214 \\
\hline $\boldsymbol{\eta}_{\mathbf{1}}(\mathbf{\%})$ & 5.89 & 5.73 & 5.34 & 2.79 \\
\hline Average $\boldsymbol{\eta}_{\mathbf{1}}(\mathbf{\%})$ & \multicolumn{5}{|c}{$5.65 \%$} & $/$ \\
\hline
\end{tabular}

(mo represents the mass of modified and unmodified fiber ball, $\mathrm{m}_{1}$ represents the mass of samples after cleaned by deionized water in ultrasonic washing units for several times, $\eta_{1}$ represents the load rate of PANI.)

Fig.1(e) exhibits the FT-IR spectra of different samples. Curves 1 and 2 reveal the spectrum of fiber ball and modified fiber ball, respectively. The adsorption peaks appeared at Curves 1 and 2 located at $1722 \mathrm{~cm}^{-1}, 1411 \mathrm{~cm}^{-1}$ and $725 \mathrm{~cm}^{-1}$ are corresponding to $\mathrm{C}=\mathrm{O}$ stretching vibrations, $\mathrm{C}-\mathrm{O}$ stretching vibrations of carboxylic acids and $\mathrm{OH}$ out-of-plane bending vibration, respectively [25]. Compared with Curve 1, the adsorption peaks in Curve 2 are enhanced apparently, which may arise from the 
1 formation of carboxyl and hydroxyl radicals in the fiber balls under the reaction of

2 strong oxidants [26-28]. In a word, it indicates that the physical and chemical bonding

3 forces of the fibers are enhanced and the surface atoms are more active after being

4 modified with $10 \mathrm{~g} \cdot \mathrm{L}^{-1} \mathrm{H}_{2} \mathrm{O}_{2}$. In Fig.1(e), Curve 3 is the FT-IR spectrum of PANI

5 powder and the characteristic peaks located at $1577 \mathrm{~cm}^{-1}$ and $1501 \mathrm{~cm}^{-1}$ are

6 corresponding to the stretching vibrations of $\mathrm{C}=\mathrm{C}$ bond on reduction units benzene

7 structure $(\mathrm{NH}-\mathrm{B}-\mathrm{NH})$ and oxidation units quinone structure $(\mathrm{N}=\mathrm{Q}=\mathrm{N})$, where $\mathrm{Q}, \mathrm{B}$

8 represent quinone ring and benzene ring, respectively $[11,29]$. Both the reduction units

9 (NH-B-NH) and oxidation units $(\mathrm{N}=\mathrm{Q}=\mathrm{N})$ appearing in the PANI means that the PANI

10 we fabricated can be further oxidized or reduced. The peak at $1306 \mathrm{~cm}^{-1}$ is related to

11 the $\mathrm{C}-\mathrm{N}$ bond stretching vibration on the benzene ring, and the peak at $1123 \mathrm{~cm}^{-1}$ is due

12 to the characteristic absorption of $\mathrm{C}-\mathrm{H}$ vibration in $\mathrm{B}-\mathrm{NH}^{+}=\mathrm{Q}[29,30]$. Curves 4 and 5

13 in Fig.1(e) exhibit the FT-IR spectrum of PANI/FB and PANI/m-FB composites,

14 respectively, and it can be obviously seen that the peaks related to the groups of PANI

15 also appeared in the FT-IR of composites.

16 In our experiment, we adopt the method of standard concentration curve to label 17 the concentration of $\mathrm{Cr}(\mathrm{VI})$ in aqueous solution.

Fig.S1(a) is the optical absorption curves for different $\mathrm{Cr}(\mathrm{VI})$ concentrations and

it can be noticed that as the $\mathrm{Cr}(\mathrm{VI})$ concentration increases, the optical absorption enhances as well. In term of the relation between peak values at $350 \mathrm{~nm}$ with the $\mathrm{Cr}(\mathrm{VI})$ concentration in Fig.S1(a), a linear fitting curve has been plotted in Fig.S1(b) and the equation can be derived as following:

$$
\mathrm{Y}=0.02702 \mathrm{X}+0.06551
$$

where $\mathrm{Y}$ and $\mathrm{X}$ represent the optical absorbance and concentration of $\mathrm{Cr}(\mathrm{VI})$ in aqueous solution, respectively. 
2 put into $150 \mathrm{~mL} \mathrm{Cr}(\mathrm{VI})$ solution with the initial concentration $\left(\mathrm{C}_{0}\right)$ of $10 \mathrm{mg} \cdot \mathrm{L}^{-1}$,

For the removal and adsorption experiment, $1.0 \mathrm{~g}$ PANI/m-FB composites were $\mathrm{pH}=5.0$. And then, $3 \mathrm{~mL}$ of the reaction solution was taken out for optical absorption measurement at predetermined intervals to determine the concentration of $\mathrm{Cr}(\mathrm{VI})$ in aqueous solution.

The removal capacity (Q) is mainly used to characterize the amount of $\mathrm{Cr}(\mathrm{VI})$ removal of the adsorbent per gram at equilibrium $\left(\mathrm{mg} \cdot \mathrm{g}^{-1}\right)$ and it can be calculated by using equation (2):

$$
Q=\frac{\left(C_{0}-C_{e}\right) V}{m}
$$

where $\mathrm{V}$ is the volume of solution ( $\mathrm{L}), \mathrm{m}$ is the mass of PANI/ $\mathrm{m}-\mathrm{FB}$ composites $(\mathrm{g})$, $\mathrm{C}_{0}$ and $\mathrm{C}_{\mathrm{e}}$ are corresponding to the initial and equilibrium $\mathrm{Cr}(\mathrm{VI})$ concentration in aqueous solution $\left(\mathrm{mg} \cdot \mathrm{L}^{-1}\right)$, respectively.

The removal percentage $(\mathrm{R})$ is usually used to characterize the adsorption efficiency and it can be calculated by equation (3):

$$
\mathrm{R}=\frac{\left(\mathrm{C}_{0}-\mathrm{C}_{\mathrm{e}}\right)}{\mathrm{C}_{0}} \times 100 \%
$$

where $\mathrm{C}_{0}$ and $\mathrm{C}_{\mathrm{e}}\left(\mathrm{mg} \cdot \mathrm{L}^{-1}\right)$ are the concentration of $\mathrm{Cr}(\mathrm{VI})$ before and after reaction, respectively.

Fig.1(f) shows the relation between the contact time and remaining $\mathrm{Cr}(\mathrm{VI})$ concentration in the solution after reaction with $\mathrm{PANI} / \mathrm{m}-\mathrm{FB}$ composites. It can be observed that in the beginning stage $(0 \sim 10 \mathrm{~min})$, the remanent $\mathrm{Cr}(\mathrm{VI})$ concentration in aqueous solution declines rapidly, and then the downtrend becomes slowly until equilibrium after reaction for $5 \mathrm{~h}$. As can be seen in Fig.S2, the $\mathrm{Cr}(\mathrm{VI})$ solution become colourless and an almost 100\% removal percentage was obtained after reaction with composites. This result demonstrated that this kind of composite can effectively remove $\mathrm{Cr}(\mathrm{VI})$ in one step. 
Fig.2(a) shows the SEM image of PANI/m-FB composites after $\mathrm{Cr}(\mathrm{VI})$ removal and it reveals that the morphology of composites changed scarcely compared with the morphology of composites without reaction with $\mathrm{Cr}(\mathrm{VI})$ (Fig.1(c)). The insert figure in Fig.2(a) shows the element mapping of the composites after reaction with $\mathrm{Cr}(\mathrm{VI})$ and it can be observed that there exists $\mathrm{Cr}$ element besides the inherent elements of composites like $\mathrm{C}$ and $\mathrm{N}$. It directly confirms that the lost $\mathrm{Cr}$ in aqueous solution has been indeed absorbed by PANI/m-FB composites. What's more, Fig.2(b) shows the XPS spectrum of the PANI/m-FB composites after reaction with $\mathrm{Cr}(\mathrm{VI})$ solution. The binding energies locating at $577.3 \mathrm{eV}$ and $588 \mathrm{eV}$ can be assigned to $\mathrm{Cr} 2 \mathrm{p}_{3 / 2}$ and $\mathrm{Cr}$ $2 \mathrm{p}_{1 / 2}$, respectively, which are corresponding to $\mathrm{Cr}(\mathrm{III})$ and $\mathrm{Cr}(\mathrm{VI})$ [5,31,32]. It was reported that the peak at $577.3 \mathrm{eV}$ can be attributed to $\mathrm{Cr}(\mathrm{III})$ by analogy with other chromium compounds $[32,33]$. Therefore, it can verify that after treated with the PANI/m-FB composites, $\mathrm{Cr}(\mathrm{VI})$ in aqueous solution has been adsorbed on the composites and been reduced to $\mathrm{Cr}$ (III) synchronously [34,31].

To investigate the effect of $\mathrm{pH}$ value and initial $\mathrm{Cr}(\mathrm{VI})$ concentration on $\mathrm{Cr}(\mathrm{VI})$ removal capacity, $1.0 \mathrm{~g}$ PANI/m-FB composites were put into $150 \mathrm{~mL}$ of $\mathrm{Cr}(\mathrm{VI})$ solution with different $\mathrm{pH}$ values and concentrations, respectively. Based on the results before, the removal capacity is little difference between reaction for $1 \mathrm{~h}$ and $5 \mathrm{~h}$, so we choose the result of reaction for $1 \mathrm{~h}$ as the removal capacity.

Fig.2(c) shows the relationship of residual concentration with the $\mathrm{pH}$ values and it can be seen that when the $\mathrm{pH}$ value is below 7.0, the remanent concentration of $\mathrm{Cr}(\mathrm{VI})$ in aqueous solution declines until the $\mathrm{pH}$ value increases to 5.0 and then increases slightly in the $\mathrm{pH}$ range of 5.0 to 7.0. When the $\mathrm{pH}$ value is greater than 7.0, the residual concentration of $\mathrm{Cr}(\mathrm{VI})$ in aqueous solution increases rapidly. To further investigate the influence of $\mathrm{pH}$ value, the removal capacities of $\mathrm{PANI} / \mathrm{m}-\mathrm{FB}$ composites with different 
$1 \mathrm{pH}$ values are calculated by Eq.(2) and illustrated in Fig.2(d). As we can see, the

2 optimum $\mathrm{pH}$ value is 5.0 and the removal capacity is about $29.9 \mathrm{mg} \cdot \mathrm{g}^{-1}$. Also, in

3 Fig.2(d), it is obvious to see that the removal capacity of composites is stronger in acid

4 condition rather than in alkaline condition.

5 According to the previous literatures, the main existence forms of $\mathrm{Cr}(\mathrm{VI})$ in water

6 are chromate $\left(\mathrm{CrO}_{4}{ }^{2-}\right)$, dichromate $\left(\mathrm{Cr}_{2} \mathrm{O}_{7}{ }^{2-}\right)$, hydrogen chromate $\left(\mathrm{H}_{2} \mathrm{CrO}_{4}\right.$ and $\mathrm{HCrO}_{4}{ }^{-}$

7 ), which are dependent on $\mathrm{pH}$ values $[35,36]$. The balance relationships between these

8 forms are shown as following [37,38]:

9

10

$$
\begin{aligned}
\mathrm{H}_{2} \mathrm{CrO}_{4} \leftrightarrow \mathrm{HCrO}_{4}^{-}+\mathrm{H}^{+}, & \mathrm{pKa}_{1}=0.8 \\
2 \mathrm{HCrO}_{4}^{-} \leftrightarrow \mathrm{Cr}_{2} \mathrm{O}_{7}^{2-}+\mathrm{H}_{2} \mathrm{O}, & \mathrm{pKa}_{2}=-1.52 \\
\mathrm{HCrO}_{4}^{-} \leftrightarrow \mathrm{CrO}_{4}^{2-}+\mathrm{H}^{+}, & \mathrm{pKa}_{3}=6.5
\end{aligned}
$$

The distribution of different forms of $\mathrm{Cr}(\mathrm{VI})$ at different $\mathrm{pH}$ can be calculated by Eqs.(4), (5) and (6) using dissociation constant pKa1, pKa2, and pKa3, and the forms distribution diagram of $\mathrm{Cr}(\mathrm{VI})$ are illustrated in Fig.2(e). It can be seen that in the solution of strong acid $(\mathrm{pH}<2.0)$, the main existence form of $\mathrm{Cr}(\mathrm{VI})$ is $\mathrm{H}_{2} \mathrm{CrO}_{4}$. When $\mathrm{pH}$ value ranges from 2.0 to 7.0 , the dominant forms of $\mathrm{Cr}(\mathrm{VI})$ are $\mathrm{HCrO}_{4}{ }^{-}$and $\mathrm{Cr}_{2} \mathrm{O}_{7}{ }^{2-}$ . And the only stable form of $\mathrm{Cr}(\mathrm{VI})$ in alkaline solution $(\mathrm{pH}>7.0)$ is $\mathrm{CrO}_{4}{ }^{2-}$.

It is important to know that the different forms of $\mathrm{Cr}(\mathrm{VI})$ have different oxidationreduction reaction capacities. According to Eq.(4), in spite that $\mathrm{H}_{2} \mathrm{CrO}_{4}$ is hard to be adsorbed when $\mathrm{pH}$ value is below 2.0, some parts of $\mathrm{H}_{2} \mathrm{CrO}_{4}$ could transform to $\mathrm{HCrO}_{4}^{-}$ in aqueous solution and would be adsorbed and reduced, which can account for the lower removal capacity of PANI/m-FB composites in strong acid solution. When $\mathrm{pH}$ value is between 2.0 to 6.8 , it is reported that $\mathrm{HCrO}_{4}^{-}$and $\mathrm{Cr}_{2} \mathrm{O}_{7}^{2-}$ have a higher redox potential, so $\mathrm{HCrO}_{4}^{-}$and $\mathrm{Cr}_{2} \mathrm{O}_{7}{ }^{2-}$ are easier to be reduced to $\mathrm{Cr}(\mathrm{III})$ after $\mathrm{PANI} / \mathrm{m}-\mathrm{FB}$ composite is added. As a result, the removal capacity of PANI/m-FB composite is 
1 higher in acid solution. Inversely, $\mathrm{CrO}_{4}^{2-}$ in alkaline solution is hard to be reduced to

$2 \mathrm{Cr}(\mathrm{III})$ due to the lower redox potential $[39,35]$, and it would cause a lower removal

3 capacity of $\mathrm{PANI} / \mathrm{m}-\mathrm{FB}$ composites as $\mathrm{pH}$ value increases. The transformation of

$4 \quad \mathrm{Cr}(\mathrm{VI})$ can be seen as follows $[5,16]$ :

$$
\begin{array}{ll}
\mathrm{Cr}_{2} \mathrm{O}_{7}^{2-}+6 \mathrm{e}^{-}+14 \mathrm{H}^{+} \rightarrow 2 \mathrm{Cr}^{3+}+7 \mathrm{H}_{2} \mathrm{O} & \left(\mathrm{E}^{0}=1.33 \mathrm{~V}\right) \\
2 \mathrm{HCrO}_{4}^{-}+6 \mathrm{e}^{-}+14 \mathrm{H}^{+} \rightarrow 2 \mathrm{Cr}^{3+}+8 \mathrm{H}_{2} \mathrm{O} & \left(\mathrm{E}^{0}=1.33 \mathrm{~V}\right) \\
\mathrm{CrO}_{4}^{2-}+3 \mathrm{e}^{-}+4 \mathrm{H}_{2} \mathrm{O} \rightarrow \mathrm{Cr}^{3+}+80 \mathrm{H}^{-} & \left(\mathrm{E}^{0}=-0.13 \mathrm{~V}\right)
\end{array}
$$

Hence, we can infer the change trends of $\mathrm{Cr}(\mathrm{VI})$ forms in aqueous solution after reaction with PANI/m-FB composite, just like Fig.2(f) shown. In Fig.2(f), the dot lines and dash lines represent the concentration of different forms of $\mathrm{Cr}(\mathrm{VI})$ including $\mathrm{H}_{2} \mathrm{CrO}_{4}, \mathrm{HCrO}_{4}^{-}, \mathrm{Cr}_{2} \mathrm{O}_{7}{ }^{2-}$ and $\mathrm{CrO}_{4}{ }^{2-}$, respectively, and the solid line represents the total concentration of $\mathrm{Cr}(\mathrm{VI})$ in aqueous solution, which is the sum of the other four forms. Notably, the solid line in Fig.2(f) has a similar tendency to Fig.2(c).

On the other hand, PANI would be protonated in acid solution and the protonation of PANI is conductive to accelerating the oxidation-reduction reaction for the reason that the doped polyaniline chain with a large amount of positive charges $\left(\mathrm{N}^{+}\right)$could combine more negative ions $\mathrm{HCrO}_{4}^{-}, \mathrm{Cr}_{2} \mathrm{O}_{7}{ }^{2-}, \mathrm{CrO}_{4}{ }^{2-}$ and it contributes to reducing $\mathrm{Cr}(\mathrm{VI})$ to $\mathrm{Cr}(\mathrm{III})$ [5]. In addition, as negative ions, the main method for $\mathrm{Cr}(\mathrm{VI})$ to be adsorbed on the surface of $\mathrm{PANI} / \mathrm{m}-\mathrm{FB}$ is electrostatic interaction. As $\mathrm{pH}$ increases, the protonation extent of PANI declines and the concentration of $\mathrm{OH}^{-}$in aqueous solution increases. In consequence, more $\mathrm{OH}^{-}$would compete the adsorption sites of PANI/mFB with negative ions including $\mathrm{HCrO}_{4}^{-}, \mathrm{Cr}_{2} \mathrm{O}_{7}{ }^{2-}, \mathrm{CrO}_{4}{ }^{2-}$ and cause the low removal capacity of $\mathrm{Cr}(\mathrm{VI})$ in alkaline condition. Furthermore, the modified fiber ball, which has the large specific surface area and excellent acid-resistivity, also contributes to adsorbing heavy metal ions in the acid solution. 
Fig.2(g) exhibits XPS spectra for Cr 2p spectra of PANI/m-FB composites after reaction with $\mathrm{Cr}(\mathrm{VI})$ at $\mathrm{pH}=1.0,5.0$ and 11.0 , respectively. In acid condition, two typical Cr 2p XPS peaks appeared in Curves 1 and 2 in Fig.2(g), and the peaks at 577.3 $\mathrm{eV}$ and $588 \mathrm{eV}$ are corresponding to $\mathrm{Cr}(\mathrm{III})$ and $\mathrm{Cr}(\mathrm{VI})$, respectively. Comparing Curves 1 and 2, it can be seen that the relative intensity of $\mathrm{Cr}(\mathrm{III})$ is higher at $\mathrm{pH}=5.0$ than that at $\mathrm{pH}=1.0$, indicating that more reduced $\mathrm{Cr}(\mathrm{III})$ were adsorbed in the solution with $\mathrm{pH}$ value of 5.0.

It is reported that the dominant form of reduced $\mathrm{Cr}(\mathrm{III})$ is gradually changed from $\mathrm{Cr}^{3+}(\mathrm{pH}<4)$ to divalent $\mathrm{Cr}(\mathrm{OH})^{2+}\left(\mathrm{pH}\right.$ between 4.0 and 4.5) and monovalent $\mathrm{Cr}(\mathrm{OH})_{2}{ }^{+}$ ( $\mathrm{pH}$ between 5.5 and 7.0) form as $\mathrm{pH}$ increases [11]. That means when $\mathrm{pH}$ is below 4.0, the reduced $\mathrm{Cr}(\mathrm{III})$ dominantly existed in $\mathrm{Cr}^{3+}$ form with 3 positive charges, which is unfavourable to be adsorbed because the increase of electrostatic repulsion between $\mathrm{Cr}^{3+}$ and protonated PANI would overcome the chelation interaction between $\mathrm{Cr}^{3+}$ and PANI [16]. However, as $\mathrm{pH}$ value increases to 5.0, the electrostatic repulsion between the $\mathrm{PANI} / \mathrm{m}-\mathrm{FB}$ composites and $\mathrm{Cr}(\mathrm{III})$ is decreased gradually due to the decrease amount of positive charges in the form of Cr(III), and it would cause a little effect on chelation interaction, which is considered as the main factor to adsorb reduced $\mathrm{Cr}$ (III) in acid solution. Hence, it could explain the adsorption of reduced $\mathrm{Cr}(\mathrm{III})$ is larger when $\mathrm{pH}$ value is 5.0 rather than 1.0 in Fig.2(g). Interestingly, in Fig.2(g), as can be seen in Curve 3, there is no obvious $\mathrm{Cr} 2 \mathrm{p}$ peak and this consequence is accord with the results exhibited in Fig.2(c) and (d), which further prove that in alkaline solution, the PANI/mFB composites are scarcely to remove $\mathrm{Cr}(\mathrm{VI})$. And based on all of these results, it can summarize that the $\mathrm{pH}$ value has a significant influence on $\mathrm{Cr}(\mathrm{VI})$ removal and the optimum $\mathrm{pH}$ value is 5.0 with the removal capacity of $29.9 \mathrm{mg} \cdot \mathrm{g}^{-1}$. 
Furthermore, initial $\mathrm{Cr}(\mathrm{VI})$ concentration in aqueous solution is also an important factor to influence the removal capacity of $\mathrm{PANI} / \mathrm{m}-\mathrm{FB}$ composites apart from $\mathrm{pH}$ value. Fig.3(a) and (b) illustrate the effect of initial $\mathrm{Cr}(\mathrm{VI})$ concentration $\left(\mathrm{C}_{0}\right)$ on the remanent concentration and removal capacity, respectively. In Fig.3(a), it can be observed that as $\mathrm{C}_{0}$ increases, the residual concentration of $\mathrm{Cr}(\mathrm{VI})$ in aqueous solution increases as well. In addition, the dashed line, $Y=0$, represents a removal percentage of $100 \%$ and it shows that the removal percentage is decreased with $\mathrm{C}_{0}$ increased. The insert picture in Fig.3(a) also illustrates that as $\mathrm{C}_{0}$ increases, the removal percentage obtained by Eq.(3) declines gradually. It can be seen that when $\mathrm{C}_{0}$ is below $10 \mathrm{mg} \cdot \mathrm{L}^{-1}$, the removal percentage can reach almost $100 \%$. In order to better understand the effect of initial $\mathrm{Cr}(\mathrm{VI})$ concentration on removal performance, the removal capacity is calculated by Eq.(2) and the results are shown in Fig.3(b). We can notice that as $\mathrm{C}_{0}$ increased, the removal capacity of composites increased as well. When $\mathrm{C}_{0}$ increases to about $200 \mathrm{mg} \cdot \mathrm{L}^{-1}$, the removal capacity reaches $291.13 \mathrm{mg} \cdot \mathrm{g}^{-1}$ and then changes scarcely with $\mathrm{C}_{0}$ increasing continually. For one thing, this may be due to the limitation of active adsorption sites on the surface of PANI/m-FB composites. In the case of high initial concentration of $\mathrm{Cr}(\mathrm{VI})$, there are not enough adsorption sites for PANI/m-FB composites to adsorb and reduce $\mathrm{Cr}(\mathrm{VI})$ anymore [16]. For another, due to the high initial concentration of $\mathrm{Cr}(\mathrm{VI})$, protonated emeraldite salt has been completely oxidized to pernigraniline base which loses the ability to reduce $\mathrm{Cr}(\mathrm{VI})[40]$.

Table 2 exhibits the removal capacities comparison of different adsorbents and according to this table, it can be concluded that the adsorbent we prepared has a relevant higher removal capacity compared with most of the other adsorbents. Besides, it also has its unique advantages which is easy to be recycled and reused so as to avoid secondary pollution during the process of application. 
1 Table 2 The removal capacity comparison with other adsorbents

\begin{tabular}{ccc}
\hline Adsorbent & $\mathrm{Q}\left(\mathrm{mg} \cdot \mathrm{g}^{-1}\right)$ & References \\
\hline PANI/modified fiber ball & 293.13 & This work. \\
Activated Carbon nanocomposites & 500 & {$[41]$} \\
Carbon nanotubes & 2.517 & {$[42]$} \\
Modified zeolites & 12.324 & {$[43]$} \\
Biosorption & 89.32 & {$[44]$} \\
Waste weed (salvinia cucullata) & 232 & {$[45]$} \\
Hollow PANI spheres & 127.88 & {$[16]$} \\
PANI coated Ethyl Cellulose & 38.76 & {$[46]$} \\
PANI/multiwalled carbon nanotubes & 75.59 & {$[47]$} \\
Polypyrrole-polyaniline nanofibers & 227 & {$[48]$} \\
Magnetite/graphene/PANI & 153.54 & {$[49]$} \\
\hline
\end{tabular}

2

As we all known, the regeneration and recycling performance is essential for industrialized application. In order to study the regeneration and recycling performance, the used PANI/m-FB composites were taken out and dried for SEM observation and EDS measurement to ascertain the change of composites before and after adsorption. Comparing Fig.1(a) and Fig.2(c), it can be seen that after reaction with $\mathrm{Cr}(\mathrm{VI})$, the morphology of PANI changes scarcely and PANI still coats on the m-FB uniformly and tightly, indicating that PANI/m-FB composites can be cyclic utilization preliminarily.

To further study the regeneration and recycling performances, one group of the used PANI/m-FB composites is regenerated by dispersion in $100 \mathrm{ml} \mathrm{H}_{2} \mathrm{SO}_{4}(1 \mathrm{M})$ for $1 \mathrm{~h}$. For comparison, we did nothing with another group of PANI/m-FB composites except for taking them out and drying. Whereafter, these two groups PANI/m-FB composites were used to deal with $\mathrm{Cr}(\mathrm{VI})$ again and the $\mathrm{Cr}(\mathrm{VI})$ concentration was determined through the same measure to explore the regeneration and recycling 
1 properties of PANI/m-FB composites. Fig.3(c) exhibits that the removal percentages of

2 PANI/m-FB composites regenerated with acid can still maintain around $90 \%$ after

3 repeated for several cycles and are always higher than the composites without acid

4 treatment.

Fig.3(d) shows the FT-IR spectra of original PANI/m-FB composites (Curve 1), PANI/m-FB composites after treating $\mathrm{Cr}(\mathrm{VI})$ (Curve 2) and PANI/m-FB composites regenerated with acid (Curve 3), respectively. Comparing Curve 1 and Curve 2, it can be found that the relative adsorption intensities at $1577 \mathrm{~cm}^{-1}$ and $1501 \mathrm{~cm}^{-1}$ in Curve 2 are higher than that in Curve 1 suggesting that some emeraldite salt has been oxidized to pernigraniline form during the process of $\mathrm{Cr}(\mathrm{VI})$ removal. In Curve 3 , the relative adsorption intensities at $1577 \mathrm{~cm}^{-1}$ and $1501 \mathrm{~cm}^{-1}$ are similar to that in Curve 1, which indicates that the fully oxidized pernigraniline is reduced to emeraldine salt again under the reaction of strong acid.

Therefore, it can be concluded that strong acid can be utilized to reduce the PANI of PANI/m-FB composites from complete oxidation state of pernigraniline to the doped intermediate oxidation state of emeraldite salt. The regeneration of PANI in acid solution is consistent with the reported in the literature previously [50]. Besides, the weights of PANI/m-FB composites weighed shown in Table 1 were measured again after reaction with $\mathrm{Cr}(\mathrm{VI})$ and treatment with acid for three times. The results were shown in Table 3 and the PANI load rate of PANI/m-FB composite still remains at the average of $5.2 \%$, indicating that this kind of $\mathrm{PANI} / \mathrm{m}-\mathrm{FB}$ composite has a promising potential to realize industrialized application.

Table 3 The PANI load rate of composites after several treatments

\begin{tabular}{l|l|l|l}
\hline & Sample-1 & Sample-2 & Sample-3 \\
\hline
\end{tabular}




\begin{tabular}{c|c|c|c}
\hline $\mathbf{m}_{\mathbf{0}} \mathbf{( g )}$ & 4.3030 & 3.5680 & 3.6771 \\
\hline $\mathbf{m}_{\mathbf{2}} \mathbf{( g )}$ & 4.5332 & 3.7476 & 3.8694 \\
\hline $\boldsymbol{\eta}_{\mathbf{2}} \mathbf{( \% )}$ & 5.34 & 5.03 & 5.23 \\
\hline
\end{tabular}

$1 \overline{\text { (mo represents the mass of modified fiber ball; } m_{2} \text { and } \eta_{2} \text { represent the mass of used }}$

2 PANI/m-FB composites and the load rate of PANI after being treated with acid several 3 times, respectively.)

4

In order to understand whether the adsorption process is physical or chemical, adsorption kinetics has been studied. For the kinetics experiment, the PANI/m-FB composites $(1.0 \mathrm{~g})$ were put into $150 \mathrm{~mL} \mathrm{Cr}(\mathrm{VI})$ solution with the initial concentration $\left(\mathrm{C}_{0}\right)$ of $10 \mathrm{mg} \cdot \mathrm{L}^{-1}, 20 \mathrm{mg} \cdot \mathrm{L}^{-1}$ and $30 \mathrm{mg} \cdot \mathrm{L}^{-1}$, respectively, and $\mathrm{pH}$ of the solution was at 5.0. The kinetic adsorption data were analyzed using two kinetic models: pseudofirst-order and pseudo-second-order kinetic models, respectively. The linear form of pseudo-first-order kinetic model is given by equation (10):

$$
\ln \left(\mathrm{q}_{\mathrm{e}}-\mathrm{q}_{\mathrm{t}}\right)=\ln \mathrm{q}_{\mathrm{e}}-\mathrm{k}_{1}
$$

And the linear form of pseudo-second-order kinetic model is given by equation (11):

$$
\frac{\mathrm{t}}{\mathrm{q}_{\mathrm{t}}}=\frac{1}{\mathrm{k}_{2} \mathrm{qe}^{2}}+\frac{\mathrm{t}}{\mathrm{q}_{\mathrm{e}}}
$$

where $\mathrm{q}_{\mathrm{e}}\left(\mathrm{mg} \cdot \mathrm{g}^{-1}\right)$ and $\mathrm{q}_{\mathrm{t}}\left(\mathrm{mg} \cdot \mathrm{g}^{-1}\right)$ are the removal capacity at equilibrium time and at random time $\mathrm{t}$, respectively, $\mathrm{k}_{1}\left(\mathrm{~min}^{-1}\right)$ and $\mathrm{k} 2\left(\mathrm{~g} \cdot \mathrm{mg}^{-1} \cdot \mathrm{min}^{-1}\right)$ are the pseudo-first-order and pseudo-second-order rate constants, respectively.

Fig.3(e) and (f) exhibit the pseudo-first-order and pseudo-second-order kinetics plot, which were fitted via Eq. (10) and Eq. (11) through the experimental data shown in Fig.S3, respectively. Notably, by fitting the data with Eq. (10) and Eq. (11), we can obtain the kinetic parameters, shown in Table 4. The pseudo-first-order kinetic model is assuming that the adsorption process is controlled by physical diffusion while the pseudo-second-order kinetic model supposes that the process is determined by chemical adsorption. From Table 4, it is obvious to see that the pseudo-second-order kinetic 
1 model shows a more accurate fit as the relative values of $\mathrm{R}^{2}$ are high and the calculated

$2 \mathrm{q}_{\mathrm{e}(\mathrm{cal})}$ (equilibrium removal capacity) values are quite close to the experimental $\mathrm{Q}$ values

3 (ESI, Fig.S3(b)). That means the pseudo-second-order kinetic model could give a better

4 explanation to the adsorption process of PANI/m-FB composites. It can be concluded

5 that the procedure may be mainly controlled by chemical adsorption and the rate

6 limiting step is chemisorption [51,40].

7

8 Table 4 Kinetic parameters for adsorption of PANI/m-FB composites

\begin{tabular}{|c|c|c|c|c|}
\hline Kinetics Models & Parameters & $10 \mathrm{mg} \cdot \mathrm{L}^{-1}$ & $20 \mathrm{mg} \cdot \mathrm{L}^{-1}$ & $30 \mathrm{mg} \cdot \mathrm{L}^{-1}$ \\
\hline \multirow{4}{*}{ Pseudo-first-order } & $q_{\text {e(cal })}\left(m g \cdot g^{-1}\right)$ & 26.591 & 42.797 & 77.507 \\
\hline & $Q\left(m g \cdot g^{-1}\right)$ & 29.161 & 53.062 & 81.618 \\
\hline & $\mathbf{R}^{2}$ & 0.96293 & 0.8599 & 0.95836 \\
\hline & $k\left(\min ^{-1}\right)$ & 1.607 & 0.091 & 0.044 \\
\hline \multirow{4}{*}{ Pseudo-second-order } & $q_{\mathrm{e}(\mathrm{cal})}\left(\mathrm{mg} \cdot \mathrm{g}^{-1}\right)$ & 29.248 & 53.533 & 84.246 \\
\hline & $Q\left(m g \cdot g^{-1}\right)$ & 29.161 & 53.062 & 81.618 \\
\hline & $\mathbf{R}^{2}$ & 0.99986 & 0.99869 & 0.99586 \\
\hline & $\mathrm{k}\left(\mathrm{g} \cdot \mathrm{mg}^{-1} \cdot \mathrm{min}^{-1}\right)$ & 0.0246 & 0.0045 & 0.0011 \\
\hline
\end{tabular}

9

Based on the above results and analysis, the possible $\mathrm{Cr}(\mathrm{VI})$ removal mechanism of PANI $/ \mathrm{m}-\mathrm{FB}$ composites is shown in Scheme 1. After being doped with protonic acid, the synthesized polyaniline in the intermediate oxidation state changes from insulator to conductive emeraldine salt. During the process of $\mathrm{Cr}(\mathrm{VI})$ removal, the emeraldite salt of intermediate oxidation state would be oxidized to pernigraniline of the fully oxidized state and simultaneously, $\mathrm{Cr}(\mathrm{VI})$ would be reduced to $\mathrm{Cr}(\mathrm{III})[13,11,52]$.

Specifically, in Scheme 1, it can be seen that $\mathrm{Cr}(\mathrm{VI})$ was first adsorbed on PANI/m-FB composites due to the large number of amine/imine groups of polyaniline, then the adsorbed $\mathrm{Cr}(\mathrm{VI})$ was rapidly reduced to $\mathrm{Cr}(\mathrm{III})$, and finally the reduced $\mathrm{Cr}(\mathrm{III})$ was immediately chelated with PANI and all of these steps of the reaction occurred 
1 simultaneously on the same sites of $\mathrm{PANI} / \mathrm{m}-\mathrm{FB}$ composites. Besides, due to the

2 reversibility of the protonated PANI, the fully oxidized pernigraniline can be

3 regenerated into conductive emeraldine salt by means of dealing with strong acid [53].

\section{Conclusions} and directly loaded on the modified fiber ball. PANI/m-FB composite with macroscale exhibits an efficient removal capacity of $\mathrm{Cr}(\mathrm{VI})$ in aqueous solution. The experiment results show that the maximum removal capacity of the composite is about 291.13 $\mathrm{mg} \cdot \mathrm{g}^{-1}$. And under the condition of $\mathrm{C}_{0}=10 \mathrm{mg} \cdot \mathrm{L}^{-1}, \mathrm{pH}=5.0$, the removal percentage is around $100 \%$. Besides, this kind of $\mathrm{PANI} / \mathrm{m}-\mathrm{FB}$ composite not only solves the problem of secondary pollution efficiently due to the macroscale of composites, but also exhibits a well performance of regeneration and multiple utilized after being treated with strong $\mathrm{Cr}(\mathrm{VI})$ from industrial waste water. visible spectrophotometer; XPS: X-ray photoelectron spectra. 
1 The datasets supporting the conclusions of this article are available in the article.

2

\section{Competing interests}

4 The authors declare that they have no competing interests.

5

$6 \quad$ Funding

7 This work was supported by the National Natural Science Foundation of China (No.

$8 \quad 51671183)$.

9

\section{Authors' contributions}

GTF and XLM designed the experiments. XLM analyzed data. GTF, XLM and SHX discussed the results and contributed to the writing of the manuscript. All authors read and approved the final manuscript.

\section{Acknowledgements}

No applicable.

\section{Author details}

${ }^{a}$ Key Laboratory of Materials Physics and Anhui Key Laboratory of Nanomaterials and Nanotechnology, Institute of Solid State Physics, Hefei Institutes of Physical Science,

21 Chinese Academy of Sciences, P. O. Box 1129, Hefei 230031, P. R. China.

${ }^{\mathrm{b}}$ University of Science and Technology of China, Hefei 230026, P. R. China. 
1 Springer Nature remains neutral with regard to jurisdictional claims in published maps

2 and institutional affiliations.

3 


\section{References}

2 1. Bhaumik M, Gupta VK, Maity A (2018) Synergetic enhancement of Cr(VI) removal

3 from aqueous solutions using polyaniline@ $\mathrm{Ni}(\mathrm{OH})_{2}$ nanocomposites adsorbent. J

$4 \quad$ Environ Chem Eng 6 (2):2514-2527

5 2. Xu C, Qiu B, Gu H, Yang X, Wei H, Huang X, Wang Y, Rutman D, Cao D, Bhana

6 S (2014) Synergistic interactions between activated carbon fabrics and toxic

7 hexavalent chromium. ECS J Solid State SC 3 (3):M1-M9

8 3. Lin C, Wang S, Huang P, Tzou Y, Liu J, Chen C-C, Chen J, Lin C (2009) Chromate

9 reduction by zero-valent $\mathrm{Al}$ metal as catalyzed by polyoxometalate. Water Res 43

$10 \quad(20): 5015-5022$

11 4. Legrand L, El Figuigui A, Mercier F, Chausse A (2004) Reduction of aqueous 12 chromate by $\mathrm{Fe}(\mathrm{II}) / \mathrm{Fe}(\mathrm{III})$ carbonate green rust: kinetic and mechanistic studies. 13 Environ Sci Technol 38 (17):4587-4595

14 5. Ding J, Pu L, Wang Y, Wu B, Yu A, Zhang X, Pan B, Zhang Q, Gao G (2018)

15 Adsorption and reduction of $\mathrm{Cr}(\mathrm{VI})$ together with $\mathrm{C}(\mathrm{III})$ sequestration by polyaniline 16 confined in pores of polystyrene beads. Environ Sci Technol 52 (21):12602-12611

17 6. Gao J, Wu Z, Chen L, Xu Z, Gao W, Jia G, Yao Y (2019) Synergistic effects of iron 18 ion and PANI in biochar material for the efficient removal of Cr (VI). Mater Lett $19 \quad 240: 147-149$

7. Jiang Y, Liu Z, Zeng G, Liu Y, Shao B, Li Z, Liu Y, Zhang W, He Q (2018) 21 Polyaniline-based adsorbents for removal of hexavalent chromium from aqueous 22 solution: a mini review. Environ Sci Pollut Res 25 (7):6158-6174 
1 8. Li T, Qin Z, Shen Y, Xu X, Liu N, Zhang Y (2019) Polyaniline nanofibers formed

2 by seed polymerization through heat treatment for synergistic enhancement of $\mathrm{Cr}(\mathrm{VI})$

3 removal. Mater Lett 252:130-133

4 9. Butler EC, Chen L, Hansel CM, Krumholz LR, Madden ASE, Lan Y (2015)

5 Biological versus mineralogical chromium reduction: potential for reoxidation by

$6 \quad$ manganese oxide. Environ Sci Process Impacts 17 (11):1930-1940

7 10. Wang Y, Rajeshwar K (1997) Electrocatalytic reduction of Cr(VI) by polypyrrole-

8 modified glassy carbon electrodes. J Electroanal Chem 425 (1-2):183-189

9 11. Guo X, Fei GT, Su H, De Zhang L (2011) High-performance and reproducible 10 polyaniline nanowire/tubes for removal of $\mathrm{Cr}(\mathrm{VI})$ in aqueous solution. J Phys Chem $11 \quad$ C $115(5): 1608-1613$

12. Freitas TV, Sousa EA, Fuzari Jr GC, Arlindo EP (2018) Different morphologies of polyaniline nanostructures synthesized by interfacial polymerization. Mater Lett $224: 42-45$

13. Chen Z, Wei B, Yang S, Li Q, Liu L, Yu S, Wen T, Hu B, Chen J, Wang X (2019) Synthesis of PANI/AlOOH composite for Cr(VI) adsorption and reduction from aqueous solutions. ChemistrySelect 4 (8):2352-2362

14. Hamadi NK, Chen XD, Farid MM, Lu MG (2001) Adsorption kinetics for the removal of chromium(VI) from aqueous solution by adsorbents derived from used tyres and sawdust. Chem Eng J 84 (2):95-105 
1 15. Rafiqi FA, Majid K (2015) Removal of copper from aqueous solution using

2 polyaniline and polyaniline/ferricyanide composite. J Environ Chem Eng 3 (4):2492-

$3 \quad 2501$

4 16. Wu H, Wang Q, Fei GT, Xu SH, Guo X, De Zhang L (2018) Preparation of Hollow

5 Polyaniline Micro/Nanospheres and Their Removal Capacity of $\mathrm{Cr}(\mathrm{VI})$ from

$6 \quad$ Wastewater. Nanoscale Res Lett 13 (1):401

7 17. Tran HD, D'Arcy JM, Wang Y, Beltramo PJ, Strong VA, Kaner RB (2011) The

8 oxidation of aniline to produce "polyaniline": a process yielding many different

9 nanoscale structures. J Mater Chem 21 (11):3534-3550

18. Joseph N, Varghese J, Sebastian MT (2015) Self assembled polyaniline nanofibers with enhanced electromagnetic shielding properties. RSC Adv 5 (26): 20459-20466

19. Ruotolo L, Liao A (2004) Reaction rate and electrochemical stability of conducting polymer films used for the reduction of hexavalent chromium. J Appl Electrochem 34 (12):1259-1263

20. Gao P, Xue G, Song X-s, Liu Z-h (2012) Depth filtration using novel fiber-ball filter media for the treatment of high-turbidity surface water. Sep Purif Technol 95:32-38

21. Yang Y, Zhang X, Wang Z (2002) Oilfield produced water treatment with surfacemodified fiber ball media filtration. Water Sci Technol 46 (11-12):165-170

22. Lee J, Johir MAH, Chinu K, Shon H, Vigneswaran S, Kandasamy J, Kim C, Shaw K (2010) Novel pre-treatment method for seawater reverse osmosis: Fibre media filtration. Desalination 250 (2):557-561 
23. Farrell ST, Breslin CB (2004) Reduction of Cr(VI) at a polyaniline film: influence

of film thickness and oxidation state. Environ Sci Technol 38 (17):4671-4676

24. Gu H, Rapole SB, Sharma J, Huang Y, Cao D, Colorado HA, Luo Z, Haldolaarachchige N, Young DP, Walters B (2012) Magnetic polyaniline nanocomposites toward toxic hexavalent chromium removal. RSC Adv 2 (29):11007-11018

25. Sadtler Research Laboratories (1970) Standard Infrared Grating Spectra, Sadtler Research Laboratorie INC., Philadelphia

26. Rahmatinejad J, Khoddami A, Mazrouei-Sebdani Z, Avinc O (2016) Polyester hydrophobicity enhancement via UV-Ozone irradiation, chemical pre-treatment and fluorocarbon finishing combination. Prog Org Coat 101:51-58

27. Ouchi A, Liu C, Kunioka M (2015) Increasing the dyeability of polyester fabrics by photochemical treatment at room-temperature using $\mathrm{H}_{2} \mathrm{O}_{2}$ in air. Green Chem 17 (1):490-498

28. Wu S (1982) Polymer Interface and Adhesion, Vol 15. MARCEL DEKKER, INC., Nwe York

29. Zhu J, Wei S, Zhang L, Mao Y, Ryu J, Karki AB, Young DP, Guo Z (2011) Polyaniline-tungsten oxide metacomposites with tunable electronic properties. J Mater Chem 21 (2):342-348

30. Mavinakuli P, Wei S, Wang Q, Karki AB, Dhage S, Wang Z, Young DP, Guo Z (2010) Polypyrrole/silicon carbide nanocomposites with tunable electrical conductivity. J Phys Chem C 114 (9):3874-3882 
31. Park D, Yun Y-S, Park JM (2008) XAS and XPS studies on chromium-binding groups of biomaterial during Cr(VI) biosorption. J Colloid Interface Sci 317 (1):5461

32. Park D, Yun Y-S, Park JM (2004) Reduction of hexavalent chromium with the brown seaweed Ecklonia biomass. Environ Sci Technol 38 (18):4860-4864

33. Kumar PA, Ray M, Chakraborty S (2007) Hexavalent chromium removal from wastewater using aniline formaldehyde condensate coated silica gel. J Hazard Mater $143(1-2): 24-32$

34. Gupta S, Babu B (2009) Removal of toxic metal Cr(VI) from aqueous solutions using sawdust as adsorbent: Equilibrium, kinetics and regeneration studies. Chem Eng J 150 (2-3):352-365

35. Sun X-F, Ma Y, Liu X-W, Wang S-G, Gao B-Y, Li X-M (2010) Sorption and detoxification of chromium(VI) by aerobic granules functionalized with polyethylenimine. Water Res 44 (8):2517-2524

36. Qiu B, Xu C, Sun D, Wei H, Zhang X, Guo J, Wang Q, Rutman D, Guo Z, Wei S (2014) Polyaniline coating on carbon fiber fabrics for improved hexavalent chromium removal. RSC Adv 4 (56):29855-29865

37. Neagu V (2009) Removal of Cr(VI) onto functionalized pyridine copolymer with amide groups. J Hazard Mater 171 (1-3):410-416

38. Zheng Y, Wang W, Huang D, Wang A (2012) Kapok fiber oriented-polyaniline nanofibers for efficient Cr(VI) removal. Chem Eng J 191:154-161 
39. Choppala G, Bolan N, Kunhikrishnan A, Skinner W, Seshadri B (2015)

Concomitant reduction and immobilization of chromium in relation to its bioavailability in soils. Environ Sci Pollut Res 22 (12):8969-8978

40. Liu B, Yang F, Zou Y, Peng Y (2014) Adsorption of phenol and p-nitrophenol from aqueous solutions on metal-organic frameworks: effect of hydrogen bonding. J Chem Eng Data 59 (5):1476-1482

41. Kaur J, Kaur M, Ubhi MK, Kaur N, Greneche J-M (2021) Composition optimization 8 of activated carbon-iron oxide nanocomposite for effective removal of $\mathrm{Cr}(\mathrm{VI})$ ions. Mater Chem Phys 258:124002

42. Mubarak NM, Thines RK, Sajuni NR, Abdullah EC, Sahu JN, Ganesan P, Jayakumar NS (2014) Adsorption of chromium(VI) on functionalized and nonfunctionalized carbon nanotubes. Korean J Chem Eng 31 (9):1582-1591

43. Szala B, Bajda T, Jeleń A (2018) Removal of chromium(VI) from aqueous solutions using zeolites modified with HDTMA and ODTMA surfactants. Clay Minerals 50 (1):103-115

44. Mishra A, Tripathi BD, Rai AK (2016) Packed-bed column biosorption of chromium(VI) and nickel(II) onto Fenton modified Hydrilla verticillata dried biomass. Ecotoxicol Environ Saf 132:420-428

45. Baral SS, Das SN, Rath P, Roy Chaudhury G, Swamy YV (2007) Removal of Cr(VI) from aqueous solution using waste weed, Salvinia cucullata. Chem Ecol 23 (2): $105-117$ 
46. Qiu B, Xu C, Sun D, Yi H, Guo J, Zhang X, Qu H, Guerrero M, Wang X, Noel N,

Luo Z, Guo Z, Wei S (2014) Polyaniline Coated Ethyl Cellulose with Improved Hexavalent Chromium Removal. ACS Sustain Chem Eng 2 (8):2070-2080

47. Wang J, Yin X, Tang W, Ma H (2015) Combined adsorption and reduction of $\mathrm{Cr}(\mathrm{VI})$ from aqueous solution on polyaniline/multiwalled carbon nanotubes composite. Korean J Chem Eng 32 (9):1889-1895

48. Bhaumik M, Maity A, Srinivasu VV, Onyango MS (2012) Removal of hexavalent chromium from aqueous solution using polypyrrole-polyaniline nanofibers. Chem Eng J 181-182:323-333

49. Harijan DKL, Chandra V (2016) Magnetite/graphene/polyaniline composite for removal of aqueous hexavalent chromium. J Appl Polym Sci 133 (39)

50. Chandrakanthi N, Careem M (2000) Preparation and characterization of fully oxidized form of polyaniline. Polym Bull 45 (2):113-120

51. Ding C, Li Y, Wang Y, Li J, Sun Y, Lin Y, Sun W, Luo C (2018) Highly selective adsorption of hydroquinone by hydroxyethyl cellulose functionalized with magnetic/ionic liquid. Int J Biol Macromol 107:957-964

52. Baruah P, Mahanta D (2016) Adsorption and reduction: combined effect of polyaniline emeraldine salt for removal of $\mathrm{Cr}(\mathrm{VI})$ from aqueous medium. Bull Mater Sci $39(3): 875-882$

53. MacDiarmid A, Manohar S, Masters J, Sun Y, Weiss H, Epstein A (1991) Polyaniline: synthesis and properties of pernigraniline base. Synth Met 41 (1-2):621626 
Figure 1 (a) SEM image of PANI/m-FB; (b) SEM image of PANI/FB; (c) enlarged

4 image of Fig.1(a); (d) the digital image of fiber ball and PANI/m-FB composite,

5 respectively; (e) FT-IR spectra of (1) FB; (2) m-FB; (3) PANI powder; (4) PANI/FB;

6 (5) $\mathrm{PANI} / \mathrm{m}-\mathrm{FB}$; (f) Changes of remanent $\mathrm{Cr}(\mathrm{VI})$ concentration at different times

$7 \quad\left(\mathrm{~T}=303 \mathrm{~K}, \mathrm{C}_{0}=10 \mathrm{mg} \cdot \mathrm{L}^{-1}, \mathrm{pH}=5.0\right)$. picture: corresponding element mappings); (b) Cr 2p XPS spectrum of PANI/m-FB after reaction with $\mathrm{Cr}(\mathrm{VI})$, where $\mathrm{Cr} 2 \mathrm{p}_{1 / 2}$ corresponds to $\mathrm{Cr}(\mathrm{VI})$ and $\mathrm{Cr} 2 \mathrm{p}_{3 / 2}$ relates to Cr(III) $\left(\mathrm{T}=303 \mathrm{~K}, \mathrm{C}_{0}=10 \mathrm{mg} \cdot \mathrm{L}^{-1}, \mathrm{pH}=5.0\right)$; Effect of $\mathrm{pH}$ value on (c) remanent concentration and (d) removal capacity of $\mathrm{Cr}(\mathrm{VI}) .\left(\mathrm{T}=303 \mathrm{~K}, \mathrm{C}_{0}=10 \mathrm{mg} \cdot \mathrm{L}^{-1}\right)$; and the relation of the concentration of different $\mathrm{Cr}(\mathrm{VI})$ forms and the $\mathrm{pH}$ value of solution; (e) Before adding PANI/m-FB composites; and (f) after adding PANI/m-FB composites; (g) Cr 2p XPS spectra of composites after reaction with $\mathrm{Cr}(\mathrm{VI})$ solution with different $\mathrm{pH}$ values (Curve 1: $\mathrm{pH}=1.0$; Curve 2: $\mathrm{pH}=5.0$; Curve 3: $\mathrm{pH}=11.0$ ).

Figure 3 Effect of initial Cr(VI) concentration on (a) remanent concentration, (insert picture: the changing of removal percentage); (b) removal capacity of $\mathrm{Cr}(\mathrm{VI})(\mathrm{T}=303$ $\mathrm{K}, \mathrm{pH}=5.0$ ) (c) The removal percentage; (d) The FT-IR spectrum of different composites $\left(\mathrm{T}=303 \mathrm{~K}, \mathrm{C}_{0}=10 \mathrm{mg} \cdot \mathrm{L}^{-1}, \mathrm{pH}=5.0\right.$ ) (Curve 1: original $\mathrm{PANI} / \mathrm{m}-\mathrm{FB}$ 
1 FB composites regenerated with acid); (e) Pseudo-first-order; (f) pseudo-second-order 2 kinetic model of composites on $\mathrm{Cr}(\mathrm{VI})$ removal.

3

4 Scheme 1 Schematic of PANI/m-FB composites on $\mathrm{Cr}(\mathrm{VI})$ removal ( $\mathrm{A}^{-}$is counterion) 

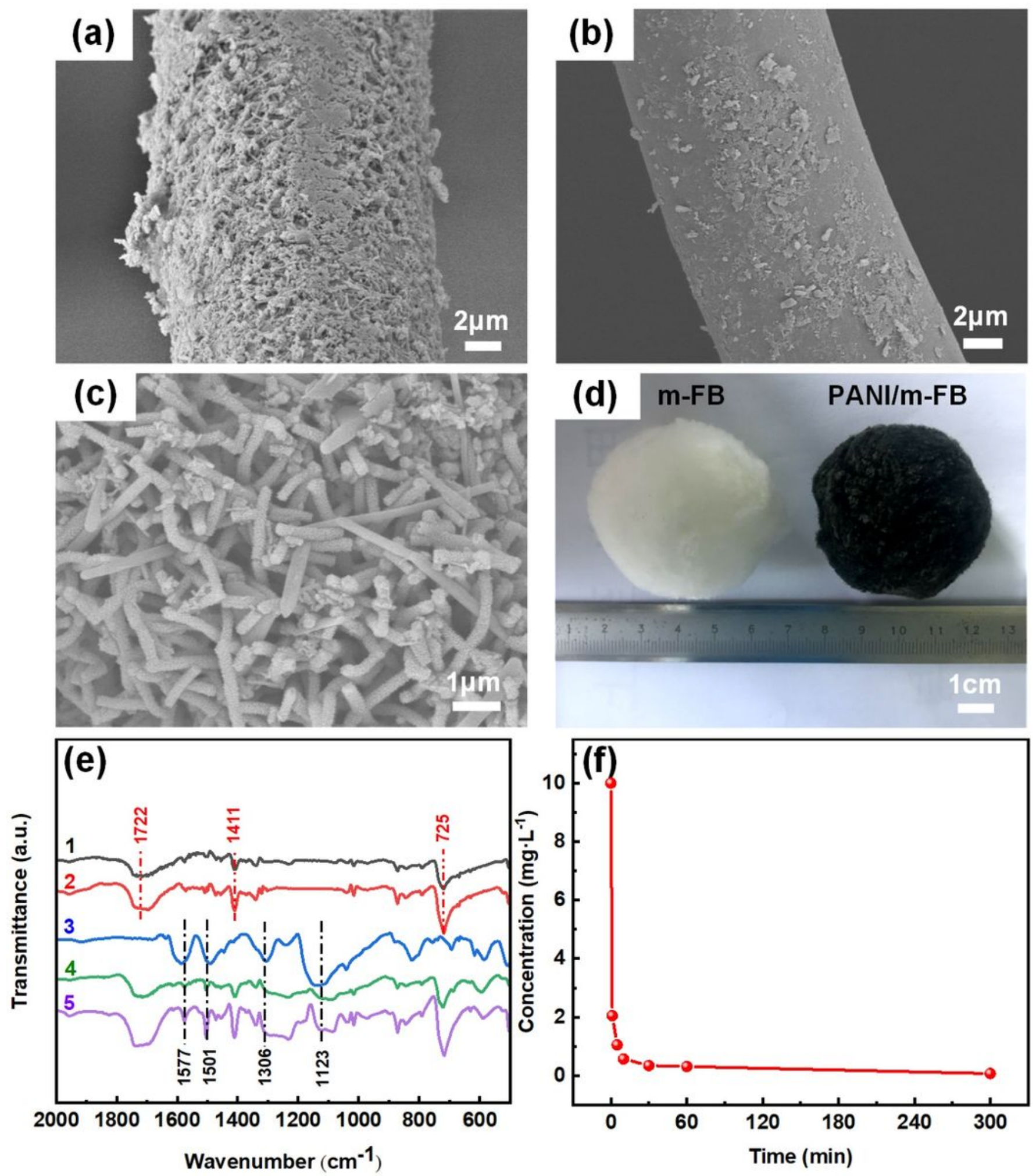

Figure 1

(a) SEM image of PANI/m-FB; (b) SEM image of PANI/FB; (c) enlarged image of Fig.1(a); (d) the digital image of fiber ball and PANI/m-FB composite, respectively; (e) FT-IR spectra of (1) FB; (2) m-FB; (3) PANI 
powder; (4) PANI/FB; (5) PANI/m-FB; (f) Changes of remanent $\mathrm{Cr}(\mathrm{VI})$ concentration at different times ( $\mathrm{T}=303 \mathrm{~K}, \mathrm{C} 0=10 \mathrm{mg} \cdot \mathrm{L}-1, \mathrm{pH}=5.0$ ).
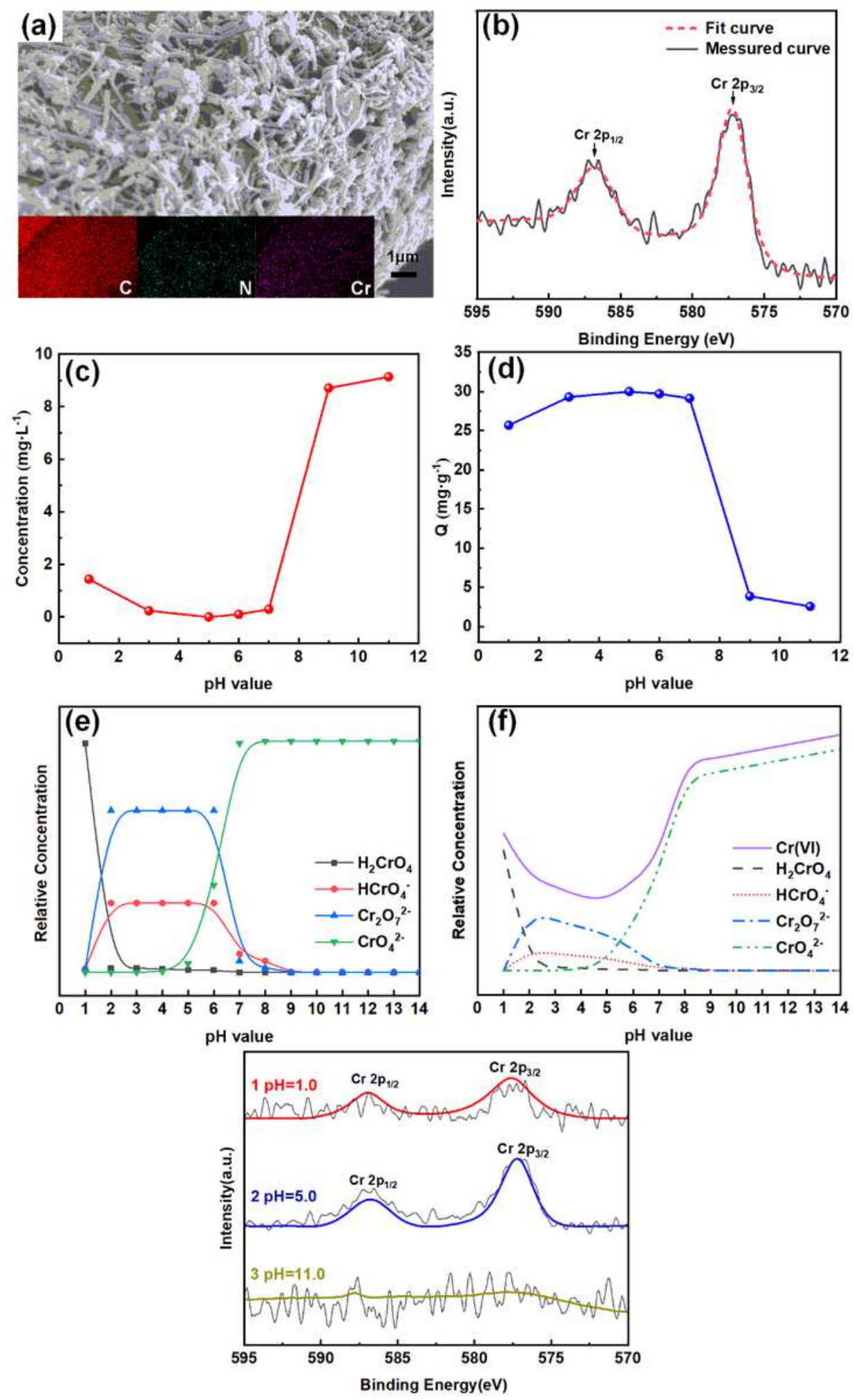

Figure 2

(a) SEM image of PANI/m-FB composites after reaction with $\mathrm{Cr}(\mathrm{VI})$ (insert picture: corresponding element mappings); (b) $\mathrm{Cr} 2 \mathrm{p}$ XPS spectrum of PANI/m-FB after reaction with $\mathrm{Cr}(\mathrm{VI})$, where $\mathrm{Cr} 2 \mathrm{p} 1 / 2$ corresponds to $\mathrm{Cr}(\mathrm{VI})$ and $\mathrm{Cr} 2 \mathrm{p} 3 / 2$ relates to $\mathrm{Cr}(\mathrm{III})(\mathrm{T}=303 \mathrm{~K}, \mathrm{C} 0=10 \mathrm{mg} \cdot \mathrm{L}-1, \mathrm{pH}=5.0)$; Effect of $\mathrm{pH}$ value on (c) 
remanent concentration and $(\mathrm{d})$ removal capacity of $\mathrm{Cr}(\mathrm{VI})$. ( $\mathrm{T}=303 \mathrm{~K}, \mathrm{CO}=10 \mathrm{mg} \cdot \mathrm{L}-1)$; and the relation of the concentration of different $\mathrm{Cr}(\mathrm{VI})$ forms and the $\mathrm{pH}$ value of solution; (e) Before adding PANI/m-FB composites; and (f) after adding PANI/m-FB composites; (g) $\mathrm{Cr} 2 \mathrm{p}$ XPS spectra of composites after reaction with $\mathrm{Cr}(\mathrm{VI})$ solution with different $\mathrm{pH}$ values (Curve 1: $\mathrm{pH}=1.0$; Curve 2: $\mathrm{pH}=5.0$; Curve 3: $\mathrm{pH}=11.0)$.
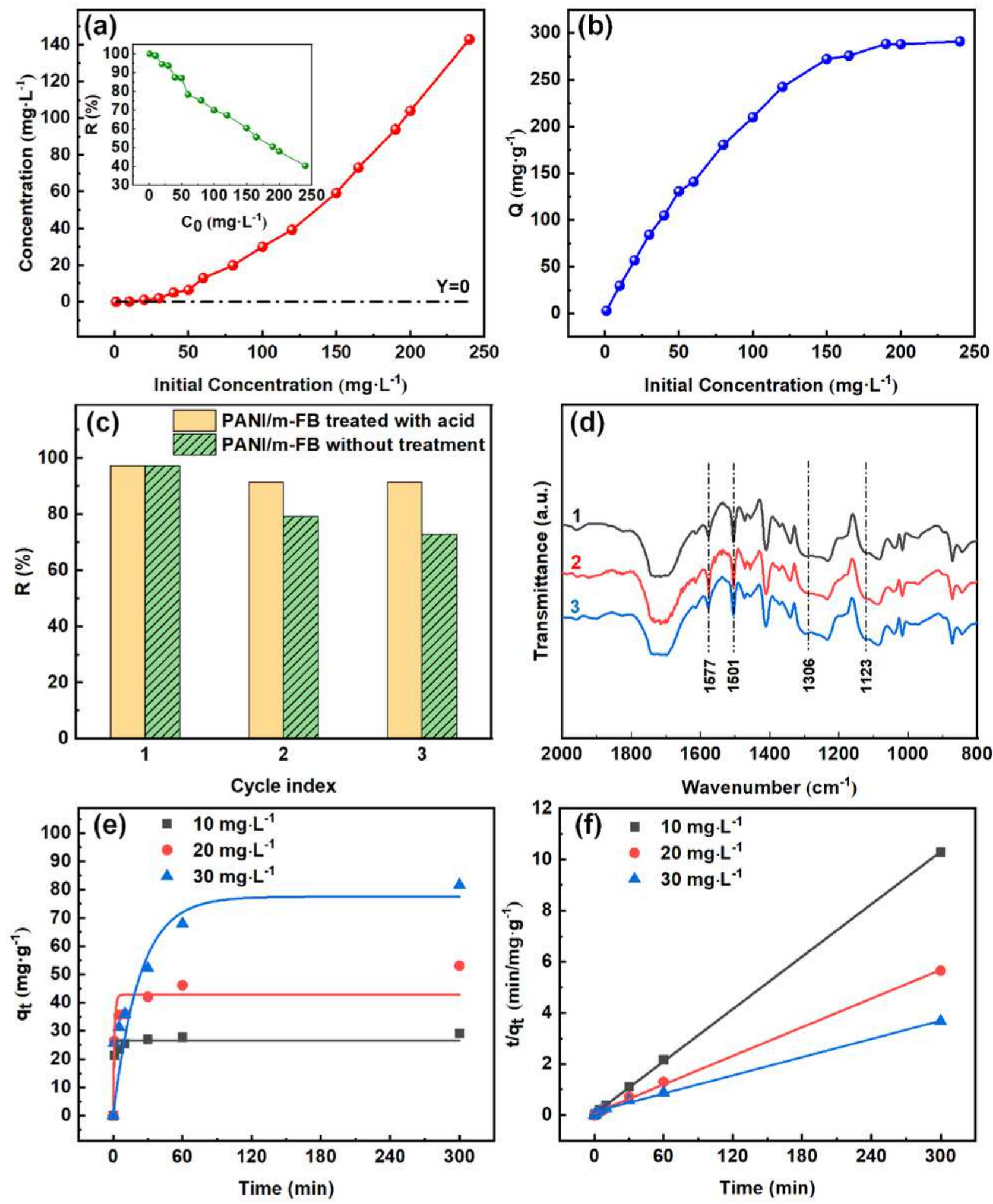

Figure 3 
Effect of initial $\mathrm{Cr}(\mathrm{VI})$ concentration on (a) remanent concentration, (insert picture: the changing of removal percentage); (b) removal capacity of $\mathrm{Cr}(\mathrm{VI})(\mathrm{T}=303 \mathrm{~K}, \mathrm{pH}=5.0)$ (c) The removal percentage; (d) The FT-IR spectrum of different composites ( $T=303 \mathrm{~K}, \mathrm{CO}=10 \mathrm{mg} \cdot \mathrm{L}-1, \mathrm{pH}=5.0$ ) (Curve 1: original PANI/mFB composites; Curve 2: PANI/m-FB composites after treating $\mathrm{Cr}(\mathrm{VI})$; Curve 3: PANI/m-FB composites regenerated with acid); (e) Pseudo-first-order; (f) pseudo-second-order kinetic model of composites on $\mathrm{Cr}(\mathrm{VI})$ removal.

\section{Supplementary Files}

This is a list of supplementary files associated with this preprint. Click to download.

- Scheme1.png

- XLMaNRLGraphicalAbstract.docx

- XLMaNRLHighlights.docx 